\title{
Population Genetic Analysis Reveals Diversity in Lasiodiplodia Species Infecting Date Palm, Citrus, and Mango in Oman and the UAE
}

A. M. Al-Sadi, Department of Crop Sciences, College of Agricultural and Marine Sciences, Sultan Qaboos University, P.O. Box 8, Al Khoud 123, Oman; A. N. Al-Wehaibi, Department of Biology, College of Science, Sultan Qaboos University; R. M. Al-Shariqi and M. S. Al-Hammadi, Abu Dhabi Food Control Authority, P.O. Box 52150, Abu Dhabi, UAE; I. A. Al-Hosni, Abu Dhabi Farmers' Services Centre, P.O. Box 62532, Abu Dhabi, UAE; and I. H. Al-Mahmooli and A. G. Al-Ghaithi, Department of Crop Sciences, College of Agricultural and Marine Sciences, Sultan Qaboos University, P.O. Box 8, Al Khoud 123, Oman

\begin{abstract}
Al-Sadi, A. M., Al-Wehaibi, A. N., Al-Shariqi, R. M., Al-Hammadi, M. S., Al-Hosni, I. A., Al-Mahmooli, I. H., and Al-Ghaithi, A. G. 2013. Population genetic analysis reveals diversity in Lasiodiplodia species infecting date palm, Citrus, and mango in Oman and the UAE. Plant Dis. 97:13631369 .

Lasiodiplodia is a common pathogen causing dieback, gummosis, or root necrosis on the three most important fruit crops in Oman and the United Arab Emirates (UAE): date palm (Phoenix dactylifera), Citrus spp., and mango (Mangifera indica). A study was conducted to examine diversity in 64 Lasiodiplodia isolates infecting date palm (24), Citrus (11), and mango (29) in Oman and the UAE. Identification based on sequences of the internal transcribed spacer (ITS) rDNA and EF1 $\alpha$ gene showed that date palm isolates belonged to L. hormozganensis (75\% of isolates) and $L$. theobromae (25\%); Citrus isolates belonged to L. hormozganensis (45\%), L. theobromae (45\%), and $L$. iraniensis (10\%); and mango isolates belonged to $L$. theobromae (59\%), L. iraniensis (34\%), and L. hormozganensis (7\%). Amplified fragment length polymorphism (AFLP) fingerprinting of the 64 isolates using four primer pair combinations produced 64 genotypes and 972 polymorphic alleles. Cluster analysis separated the isolates into four clusters representing the three species. A higher level of genetic diversity was observed in $L$. iraniensis $(0.3105)$ compared to $L$. hormozganensis $(0.2503)$ and L. theobromae $(0.2331)$ in Oman. Analysis of molecular variance (AMOVA) indicated the existence of low levels

of genetic differentiation among date palm populations of $L$. hormozganensis obtained from Oman and the UAE $\left(\mathrm{F}_{\mathrm{ST}}=0.025\right)$ and among populations of $L$. hormozganensis $(0.0485)$ and $L$. theobromae (0.0703) from date palm, Citrus, and mango. These findings imply a high rate of movement of $L$. hormozganensis and L. theobromae isolates among date palm, Citrus, and mango and between the two countries. Findings from the pathogenicity test supported the AMOVA analysis and suggested a lack of host specialization in L. hormozganensis, $L$. iraniensis, and $L$. theobromae on date palm, acid lime, and mango. Although this is the first record of $L$. hormozganensis and $L$. iraniensis in Oman, the relatively moderate level of genetic diversity in the two species compared to L. theobromae suggests that the two species have been in Oman for a long time but misidentified by morphology and ITS rDNA sequences as L. theobromae. This study is also the first record of date palm and acid lime as natural hosts for L. hormozganensis and the first record of $L$. hormozganensis in the UAE. The diversity in Lasiodiplodia species affecting date palm, Citrus, and mango in Oman and the UAE should be taken into consideration when planning future management programs for diseases caused by these pathogens.
\end{abstract}

Lasiodiplodia species are important pathogens of several plant species. They are usually associated with dieback and are consistently isolated from various tissues (twigs, bark, vascular tissue, and fruits) of affected plants. They have been reported to cause gummosis of Jatropha podagrica Hook. in China (20), root rot and collar rot disease on Jatropha curcas L. in India (22), root diseases of date palm (Phoenix dactylifera $\mathrm{L}$.) in different parts of the world $(8,34)$, and root, collar, and stem rot, dieback, and postharvest diseases on Anacardium occidentale L., Annona spp., and other species $(19,21,28)$.

In Oman, Lasiodiplodia theobromae (Pat.) Griffon \& Maubl. is a common pathogen in a number of important crops, including date palms, Citrus species, mainly acid lime (Citrus aurantifolia Swingle), and mangoes (Mangifera indica L.). The pathogen was reported to cause symptoms of dieback and gummosis in acid lime and sweet lime, dieback and decline symptoms in mango, and root diseases of date palms $(2,8,24,32)$. Losses due to these diseases vary from one location and host to another, with Lasiodiplodiainduced dieback of acid lime affecting $15 \%$ of acid lime farms in Oman (Aisha Al-Ghaithi, Sultan Qaboos University, personal communication). In mango, L. theobromae has been reported to associ-

Corresponding author: A. M. Al-Sadi, E-mail: alsadi@ squ.edu.om

Accepted for publication 6 April 2013.

http://dx.doi.org/10.1094/PDIS-03-13-0245-RE

(C) 2013 The American Phytopathological Society ate with some Ceratocystis species in mango decline, a disease which killed over a quarter million mango trees in Oman in the early 2000s (2).

Cultivation of date palms, Citrus species (mainly acid lime), and mangoes is common in Oman. They are considered the three most important fruit crops in terms of cultivation and production and are usually grown on every farm. Although Lasiodiplodia species have already been reported on date palm, acid lime, and mango in Oman, it is not clear whether the three crops are attacked by the same Lasiodiplodia species. Despite studies that characterized the genetic diversity of $L$. theobromae on Pyrus, Pinus, Eucalyptus, and Acacia species from India, Venezuela, Mexico, and South Africa $(25,31)$, little is known about the genetic diversity of other Lasiodiplodia species on date palm, acid lime, and mango. Since it is common to find these crops on most farms in Oman, it is not clear whether the practice of intercropping as well as frequent exchange of plant genetic material among districts in Oman and between Oman and the United Arab Emirates (UAE) could have affected the population structure of Lasiodiplodia. Lack of knowledge in these areas is a barrier to the development of effective management programs to control Lasiodiplodia in Oman and elsewhere.

The main objective of this study was to characterize the population structure of Lasiodiplodia species associated with date palm, Citrus, and mango in Oman. Specific objectives included: (i) to characterize Lasiodiplodia species associated with date palm, Citrus, and mango in Oman; (ii) to characterize pathogenicity of $\mathrm{La}$ siodiplodia species on date palm, acid lime, and mango; and (iii) to characterize genetic diversity and genetic differentiation within and 
among populations of Lasiodiplodia species obtained from different origins and from date palm, Citrus, and mango. The results of this study will help elucidate the population structure for Lasiodiplodia species that will assist in planning future crop management programs.

\section{Materials and Methods}

Sources, isolation, and identification of Lasiodiplodia isolates. A total of 64 isolates of Lasiodiplodia obtained from date palm, Citrus, and mango were included in the study. Necrotic date palm roots were collected during previous studies in Oman (13 isolates) and the UAE (11 isolates) (8). Eleven isolates were collected during a previous study from citrus species (acid lime, sweet orange, sweet lime, and mandarin) with dieback and gummosis symptoms (Aisha Al-Ghaithi, Sultan Qaboos University, personal communication). In addition, 29 isolates of Lasiodiplodia were collected during this study from mango trees showing dieback and gummosis symptoms in Oman. All isolates were collected from 12 geographical regions in Oman (9) and the UAE (3).

Lasiodiplodia was isolated from 36 mango trees located in Seeb, Barka, and Musanaa districts of Oman. Samples of bark and wood collected from branches with gummosis symptoms were collected. Wood samples $(2 \times 4$ to $8 \mathrm{~mm})$ with lesions were surface-sterilized using $1 \%$ sodium hypochlorite. Fungi were isolated on $2.5 \%$ potato dextrose agar (PDA; Oxoid, England).

Preliminary identification of Lasiodiplodia was based on morphological characteristics $(1,15)$. However, identity of all isolates was confirmed using sequences of the internal transcribed spacer region of the ribosomal DNA (ITS rDNA) and sequences of elongation factor 1 alpha gene $(\mathrm{EF} 1 \alpha)$. Genomic DNA was extracted from the 64 isolates following a modified protocol of Lee and Taylor (23) as described by Al-Sadi et al. (12). Freeze-dried mycelium from 6-day-old cultures grown on 2.5\% PDA was ground, and then $600 \mu \mathrm{l}$ of lysis buffer $(50 \mathrm{mM}$ Tris- $\mathrm{HCl}, 50 \mathrm{mM}$ EDTA, $3 \%$ sodium dodecyl sulfate [SDS], $1 \%$ 2-mercaptoethanol) was added to $50 \mathrm{mg}$ of the mycelium. After incubation at $65^{\circ} \mathrm{C}$ for $1 \mathrm{~h}$, phenol: chloroform: isoamyl alcohol (vol/vol/vol, 25:24:1) was added, which was followed by microcentrifugation at $10,000 \times g$ for $15 \mathrm{~min}$. The supernatant was transferred into $1.5-\mathrm{ml}$ Eppendorf microcentrifuge tubes followed by repeating the purification step once. DNA was precipitated using $10 \mu \mathrm{l}$ of $\mathrm{NaAc}$ and isopropanol at $60 \%$ of the supernatant volume. The mixture was microcentrifuged at $10,000 \times$ $g$ for $2 \mathrm{~min}$. The pellet was washed in $70 \%$ ethanol and then resuspended in $100 \mu \mathrm{l}$ of TE buffer (10 mM Tris- $\mathrm{HCl}, 1 \mathrm{mM}$ EDTA). Polymerase chain reaction (PCR) mixtures and conditions of the ITS rDNA using ITS1 and ITS4 primers were as described by AlSadi et al. (13+) using PuReTaq Ready-To-Go PCR beads (GE Healthcare). The thermocycling step was as follows: $95^{\circ} \mathrm{C}$ for 10 min, followed by 35 cycles of $95^{\circ} \mathrm{C}(30 \mathrm{~s}), 55^{\circ} \mathrm{C}(30 \mathrm{~s})$, and $72^{\circ} \mathrm{C}$ $(90 \mathrm{~s})$; and a final extension step at $72^{\circ} \mathrm{C}(10 \mathrm{~min})$. PCR of EF1 $\alpha$ gene was conducted using primers EF1-728F (CATCGAGAA GTTCGAGAAGG) and EF1-986R (TACTTGAAGGAACCC TTACC) (17). PCR mixture was as described by Al-Sadi et al. (13). However, PCR conditions consisted of denaturation at $94^{\circ} \mathrm{C}$ for $4 \mathrm{~min}$, followed by 35 cycles of denaturation at $94^{\circ} \mathrm{C}$ for $30 \mathrm{~s}$, annealing at $60^{\circ} \mathrm{C}$ for $30 \mathrm{~s}$, and extension at $72^{\circ} \mathrm{C}$ for $60 \mathrm{~s}$. This was followed by extension at $72^{\circ} \mathrm{C}$ for $10 \mathrm{~min}$.

The PCR products of the ITS rDNA and the EF1 $\alpha$ genes for all isolates were purified from dNTPs using a QIAquick PCR Purification kit (QIAGEN) following the manufacture's protocol. The purified samples were sent for sequencing to Macrogen Inc. (Korea).

The resulting sequences were aligned and then compared to each other and to worldwide collections of sequences deposited at the National Center for Biotechnology Information (NCBI) using BLAST search. A neighbor-joining tree was constructed based on the matrix of pairwise distances obtained using the Kimura 2 parameter evolutionary model (Mega 5; K. Tamura, D. Peterson, N. Peterson, G. Stecher, M. Nei, and S. Kumar, 2011). Bootstrap 70\% majority-rule consensus trees were generated using 1,000 replications.
Pathogenicity test. Pathogenicity of the three species of Lasiodiplodia recovered in this study was tested on 1-year-old date palm, mango, and acid lime seedlings. The date palm seedlings were raised from seeds of cv. Kalas, mango were raised from seeds of Indian cultivars, and acid lime material was from vegetative cuttings obtained from Omani limes. All seedlings were grown in a potting medium and sand ( $\mathrm{vol} / \mathrm{vol}, 1: 1)$, the date palm seedlings in $550 \mathrm{~cm}^{3}$ pots, the mango and acid lime seedlings in $1,800 \mathrm{~cm}^{3}$ pots. Five isolates of $L$. hormozganensis, three isolates of $L$. iraniensis, and two isolates of $L$. theobromae were used in the pathogenicity tests. A $5 \mathrm{~mm}^{2}$ wound was made at the base of the stems of mango and acid lime seedlings, and a 5-mm-diameter mycelial plug from the edge of a 7-day-old PDA culture of an isolate of Lasiodiplodia was placed on the wound (10). The mycelial plug was covered with moist sterile cotton to prevent desiccation. Date palm seedlings were inoculated as described by Al-Sadi et al. (8). A 5-mm-diameter disc from a 7-day-old PDA culture of an isolate of Lasiodiplodia was placed on surface-wounded date palm roots and wrapped using Parafilm. Seedlings were placed in a glasshouse at $25^{\circ} \mathrm{C}$ in a completely randomized design. Date palm, mango, and acid lime seedlings inoculated with PDA plugs without fungi as previously described served as controls. There were three replicate seedlings per isolate for mango and acid lime, and five replicate seedlings per isolate for date palm. The pathogenicity test was repeated at least once. Inoculated seedlings were irrigated every 2 days. The percentage of seedlings developing symptoms of wilt or death was recorded on a weekly basis for 2 months. Isolations were established from seedlings developing any of the above symptoms in order to confirm association of the inoculated fungi with the observed symptoms. The isolations were done from lesions of symptomatic wood of wilting acid lime and mango seedlings above the inoculation point and from roots of wilting date palm seedlings as explained previously. Identity of isolates of $L a$ siodiplodia was confirmed by comparing them morphologically to the isolates used for inoculation. In addition, identity of three randomly selected isolates from each Lasiodiplodia species inoculated on a host plant was confirmed by amplification and sequencing of the $\mathrm{EF} \alpha 1$ gene as explained previously.

AFLP fingerprinting of Lasiodiplodia. Amplified fragment length polymorphism (AFLP) was used to examine genetic diversity in 64 isolates of Lasiodiplodia following the modified protocol as described by Al-Sadi et al. (9) using FAM-6-labeled EcoRIAGX selective primers. Approximately $200 \mathrm{ng}$ of DNA was digested for $90 \mathrm{~min}$ at $37^{\circ} \mathrm{C}$ using the enzymes EcoRI and MseI (NEB, Frankfurt, Germany). A trial using AFLP fingerprinting was performed on a random sample of eight isolates of Lasiodiplodia and using 12 primer pair combinations $(2 \mathrm{EcoRI}+3 \times 6 \mathrm{MseI}+3)$. Of these, the four primer pair combinations that produced the highest number of polymorphic alleles were selected to analyze the genetic diversity among species of the 64 isolates of Lasiodiplodia.

Preselective amplification reaction mixtures consisted of PuReTaq Ready-To-Go PCR beads (HVD Life Sciences, Vienna, Austria), EcoRI+A (5'-GACTGCGTACCAATTCA-3') and MseI-C (5'GATGAGTCCTGAGTAAC-3') primers, restriction/ligation mix, and with Milli-Q water added to a volume of $25 \mu \mathrm{l}$ (3). The cycling profile was as described by Al-Sa'di et al. (3).

The preselective amplification product was diluted and then a selective amplification reaction performed using FAM-6-labeled EcoRI-AGA selective primer and MseI-CAA, CAT, CTG, and CGT primers. The selective amplification reaction mixture was carried out as described by Al-Sadi et al. (9), while the PCR reaction conditions were as described by Al-Sa'di et al. (3). Fragment analysis of the PCR products from the selective amplification was carried out at Macrogen Inc. (Korea) using ABI 3730XL (Applied Biosystems, Carlsbad, CA).

Analysis of AFLP data. A binary scoring system, using 1 for presence and 0 for absence of each amplified fragment between 50 and 500 base pairs (bp) in size, was followed for the AFLP data. The number and percentage of polymorphic loci and Nei (26) gene diversity were determined for each population. Nei's gene diversity 
(26) and Nei's unbiased measures of genetic distance (27) among isolates and populations of $L$. theobromae were determined using POPGENE (v 1.32) (33). A dendrogram based on Nei's unbiased measures of genetic similarity was constructed using UPGMA (unweighted pair group method with arithmetic mean; NTSYSpc v 2.21m) (29).

Variation was partitioned among and within populations of the three Lasiodiplodia species using analysis of molecular variance (AMOVA; Arlequin v. 3.1) (18). Total genetic variance was partitioned among and within populations based on geographical origins and hosts from which the isolates were collected.

\section{Results}

Identification of Lasiodiplodia isolates. Preliminary identification of isolates from mango based on morphology showed that 29 isolates were morphologically similar to Lasiodiplodia. Confirmation of identity using sequences of the ITS region showed that the 29 belong to the genus Lasiodiplodia (morphological data not presented).

Amplification of the ITS rDNA region of 64 isolates of Lasiodiplodia showed limited (99.6 to 100\%) variation in sequences of the ITS rDNA region (sequences not provided). However, amplification of the EF1 $\alpha$ gene using EF1-728F and EF1-986R primers, followed by phylogenetic analysis of the combined EF1 $\alpha$ gene and ITS region, separated the 64 isolates into three clades (Fig. 1). The first clade consisted of 25 isolates of L. hormozganensis, which was separated from all other isolates by $77 \%$ bootstrap support. Sequences of L. hormozganensis isolates from Oman showed $100 \%$ nucleotide similarity to L. hormozganensis sequences in GenBank (e.g., GU945343 and GU945344) and only $98.4 \%$ similarity to sequences of $L$. parva isolate CBS356.59 (EF622062). The second clade consisted of 11 isolates, which were separated from other isolates by a bootstrap support of $99 \%$. These isolates shared $100 \%$ nucleotide similarity to sequences of L. iraniensis in GenBank (GU945334 and GU945336) and only 93\% to isolate CBS111530 of L. theobromae (EF622054). The remaining 28 isolates showed $100 \%$ similarity to isolate CBS 111530 of L. theobromae (EF622054). One representative sequence each of $L$. hormozganensis, L. iraniensis, and L. theobromae from Oman was deposited in GenBank under the accession numbers KC834827, KC834829, and KC834829, respectively.

Out of 24 isolates obtained from date palm, 18 were identified as L. hormozganensis and six as L. theobromae. On Citrus, five isolates were identified as L. hormozganensis, one as L. iraniensis, and five as $L$. theobromae. Of the mango isolates, 17 were from $L$. theobromae, 10 from $L$. iraniensis, and only two from $L$. hormozganensis. All three Lasiodiplodia species were detected in Oman, but only $L$. hormozganensis and $L$. theobromae were detected in the UAE.

Pathogenicity test. Date palm seedlings inoculated with five isolates of L. hormozganensis and two isolates of L. theobromae resulted in yellowing of the lower leaves, followed by wilt and seedling death of most of the inoculated plants. The root system developed necrotic lesions followed by disintegration. Mortality 2 months after inoculation with L. hormozganensis was 70 to $90 \%$ (mean $80 \%$ ), and 70 to $80 \%$ (75\%) in seedlings inoculated with $L$. theobromae. No significant difference was found among the seven isolates in the level of mortality they caused on date palm seedlings (Table 1).

All inoculated acid lime seedlings developed gummosis at the inoculation point. The percentage of seedlings developing wilt symptoms, then dying following inoculation was 30 to $73 \%$ (mean $51 \%$ ) for L. hormozganensis, $72 \%$ for L. theobromae, and 17 to $77 \%$ (mean $51 \%$ ) for L. iraniensis. There were significant differences among the isolates in the percent mortality they caused on acid lime seedlings (Table 1).

Mango seedlings were the least affected by the three pathogens. The percentage of mango seedlings developing wilt symptoms following inoculation was 15 to $32 \%$ (mean 19\%) for L. hormozganensis, $22 \%$ for $L$. theobromae, and 6 to $16 \%$ (mean $8 \%$ ) for $L$. iraniensis. There were significant differences among the isolates in the percent mortality they caused on acid lime seedlings (Table 1).

No symptoms were observed on the control plants inoculated with plugs of PDA only. Isolates of Lasiodiplodia obtained from

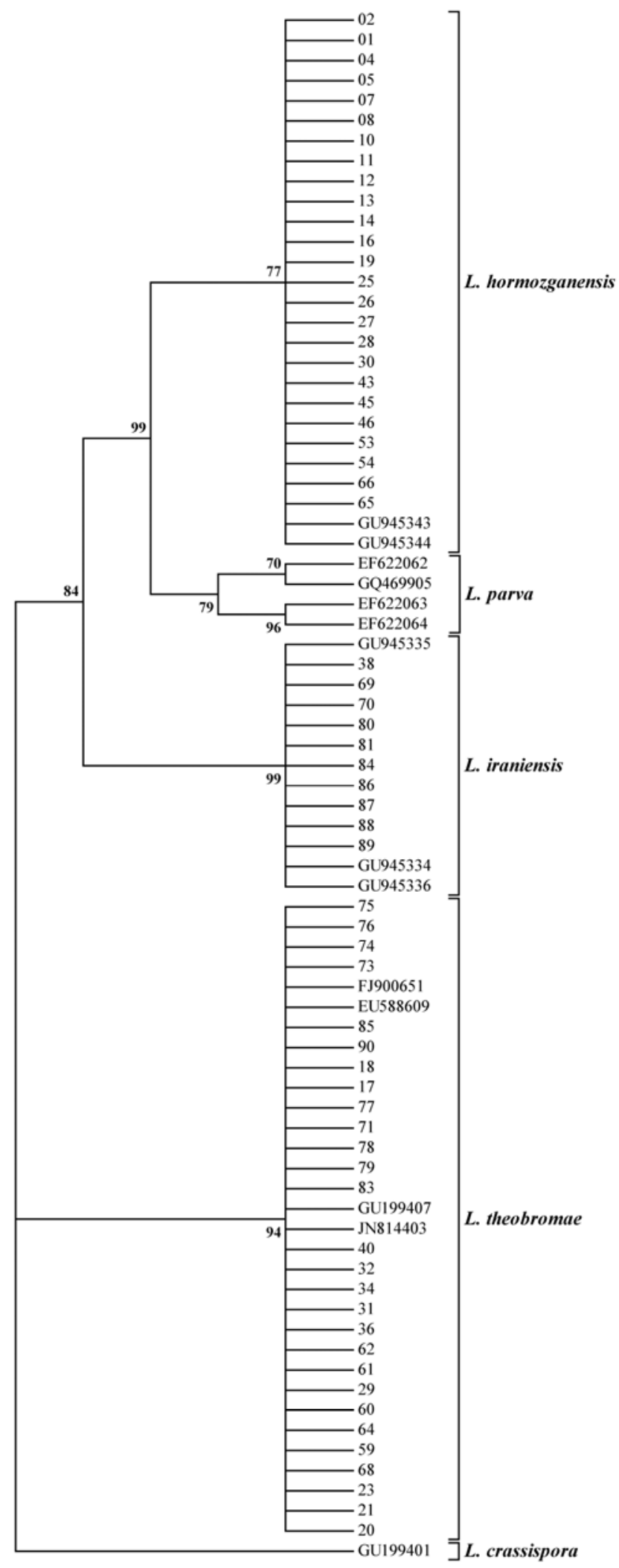

Fig. 1. Phylogram representing the relationship of Lasiodiplodia hormozganensis, $L$. iraniensis, and $L$. theobromae based on the combined EF1a gene and ITS rDNA region inferred by a heuristic tree search. Numbers within tree represent bootstrap values (values above $70 \%$ are indicated; 1,000 replications). The tree was rooted to L. crassispora. 
one host were not significantly more pathogenic on its host of origin compared to other isolates $(P>0.05$; Table 1$)$. When the inoculation trials were repeated for all isolates on the three plants, no significant differences were found between the two trials for the same isolate on the same plant (Table 1; data presented as mean of two trials).

Morphological examinations and EF $\alpha 1$ sequences showed that the same Lasiodiplodia species used for inoculation were recovered from the inoculated seedlings after isolation in PDA (data not presented).

AFLP primer pair combinations. The 12 AFLP primer pair combinations produced 49 to 238 polymorphic loci. Primer EcoRIAGA combined with $M s e I-C A A$, CAT, CGT, or CTG produced the highest number of polymorphic loci (158 to 238) and highest estimates of Nei gene diversity (Table 2 ).
Genotypic and genetic diversity. AFLP analysis of 25 isolates of $L$. hormozganensis, 28 isolates of $L$. theobromae, and 11 isolates of $L$. iraniensis showed that they consist of 25,28 , and 11 genotypes, respectively (Table 3 ). The overall level of genetic diversity of the three species was 0.2663 for L. hormozganensis, 0.2752 for L. theobromae, and 0.3105 for L. iraniensis.

Subpopulations of L. hormozganensis from date palm and Citrus growing in Oman and the UAE had moderate levels of genetic diversity ( 0.2072 to 0.2560$)$, compared to a low level of genetic diversity in the mango population (0.0878). All subpopulations of $L$. theobromae from different hosts had moderate levels of genetic diversity (0.2225 to 0.2489). The population of L. iraniensis on mangoes from Oman had a level of genetic diversity of 0.3009 (Table 3 ).

Genetic similarity and cluster analysis. Cluster analysis separated the 64 isolates of Lasiodiplodia into four main clusters, all

Table 1. Aggressiveness of three species of Lasiodiplodia on date palm, acid lime, and mango

\begin{tabular}{|c|c|c|c|c|c|}
\hline \multirow[b]{2}{*}{ Population } & \multirow[b]{2}{*}{ Isolate number } & \multirow[b]{2}{*}{ Origin } & \multicolumn{3}{|c|}{$\%$ Wilted seedlings after 2 months ${ }^{\mathrm{z}}$} \\
\hline & & & Date palm & Acid lime & Mango \\
\hline \multirow[t]{5}{*}{ L. hormozganensis } & 11 & Date palm & $70 \mathrm{a}$ & $60 \mathrm{a}$ & $15 \mathrm{ab}$ \\
\hline & 14 & Date palm & $80 \mathrm{a}$ & $73 \mathrm{a}$ & $15 \mathrm{ab}$ \\
\hline & 30 & Date palm & $80 \mathrm{a}$ & $61 \mathrm{a}$ & $32 \mathrm{a}$ \\
\hline & 54 & Citrus & $90 \mathrm{a}$ & $32 \mathrm{~b}$ & $15 \mathrm{ab}$ \\
\hline & 65 & Mango & $80 \mathrm{a}$ & $30 \mathrm{~b}$ & $19 \mathrm{ab}$ \\
\hline \multirow[t]{2}{*}{ L. theobromae } & 64 & Mango & $70 \mathrm{a}$ & $72 \mathrm{a}$ & $22 \mathrm{ab}$ \\
\hline & 18 & Date palm & $80 \mathrm{a}$ & $\mathrm{nt}$ & nt \\
\hline \multirow[t]{3}{*}{ L. iraniensis } & 38 & Citrus & $\mathrm{nt}$ & $58 \mathrm{a}$ & $10 \mathrm{~b}$ \\
\hline & 80 & Mango & nt & $77 \mathrm{a}$ & $16 a b$ \\
\hline & 86 & Mango & nt & $17 b^{*}$ & $6 b^{*}$ \\
\hline Control & $\ldots$ & $\ldots$ & 0 & 0 & 0 \\
\hline
\end{tabular}

${ }^{\mathrm{z}}$ Values represent mean of two trials for each isolate on each host plant. Control mango, acid lime, and date palm seedlings inoculated with potato dextrose agar plugs only did not show wilt or death symptoms. nt $=$ not tested. Values with the same letter in the same column, or without an asterisk in the same row, are not significantly different from each other at $P<0.05$ (Tukey's Studentized Range test, SAS).

Table 2. Evaluation of 12 primer pair combinations used to study the genetic diversity of Lasiodiplodia species ${ }^{\mathrm{y}}$

\begin{tabular}{|c|c|c|c|c|c|}
\hline No & EcoRI & MseI & $\mathbf{N P L}^{\mathrm{z}}$ & $\mathbf{P P L}^{\mathbf{z}}$ & $\mathbf{H}$ \\
\hline 1 & ACA & CAA & 76 & 81.72 & 0.2466 \\
\hline 2 & ACA & CAG & 120 & 70.59 & 0.2437 \\
\hline 3 & ACA & CAT & 75 & 59.06 & 0.1909 \\
\hline 4 & ACA & CGT & 49 & 81.72 & 0.1597 \\
\hline 5 & ACA & CTC & 92 & 62.16 & 0.2021 \\
\hline 6 & ACA & CTG & 69 & 58.47 & 0.1862 \\
\hline 7 & AGA & CAA & 238 & 95.2 & 0.361 \\
\hline 8 & AGA & CAG & 149 & 69.95 & 0.2418 \\
\hline 9 & AGA & CAT & 209 & 87.08 & 0.3147 \\
\hline 10 & AGA & CTC & 143 & 73.33 & 0.2588 \\
\hline 11 & AGA & CTG & 187 & 84.23 & 0.301 \\
\hline 12 & AGA & CGT & 158 & 73.49 & 0.2465 \\
\hline
\end{tabular}

${ }^{y}$ EcoRI and MseI primers (bold) have been selected for further analysis of the genetic diversity of Lasiodiplodia species.

${ }^{\mathrm{z}}$ NPL is the number of polymorphic loci, PPL is the percentage of polymorphic loci, and H is Nei (26) gene diversity.

Table 3. Population genetic analysis of Lasiodiplodia species obtained from date palm, mango, and Citrus ${ }^{\mathrm{Z}}$

\begin{tabular}{|c|c|c|c|c|c|c|}
\hline Population & Subpopulation & $\mathbf{N}$ & $\mathbf{g}$ & NPL & PPL & $\mathbf{H}$ \\
\hline \multirow[t]{7}{*}{ L. hormozganensis } & All & 25 & 25 & 792 & 99 & 0.2663 \\
\hline & Oman (3 hosts) & 15 & 15 & 692 & 87 & 0.2503 \\
\hline & UAE (date palm) & 10 & 10 & 624 & 78 & 0.2530 \\
\hline & Date palm (Oman) & 8 & 8 & 491 & 61 & 0.2072 \\
\hline & Date palm (Oman and UAE) & 18 & 18 & 708 & 89 & 0.2505 \\
\hline & Citrus (Oman) & 5 & 5 & 531 & 66 & 0.2560 \\
\hline & Mango (Oman) & 2 & 2 & 139 & 17 & 0.0878 \\
\hline \multirow[t]{5}{*}{ L. theobromae } & All & 28 & 28 & 830 & 98 & 0.2752 \\
\hline & Oman & 27 & 27 & 827 & 97 & 0.2331 \\
\hline & Date palm (Oman) & 6 & 6 & 562 & 66 & 0.2489 \\
\hline & Citrus (Oman) & 5 & 5 & 480 & 57 & 0.2225 \\
\hline & Mango (Oman) & 17 & 17 & 690 & 81 & 0.2465 \\
\hline \multirow[t]{2}{*}{ L. iraniensis } & Oman & 11 & 11 & 570 & 94 & 0.3105 \\
\hline & Mango (Oman) & 10 & 10 & 539 & 92 & 0.3009 \\
\hline
\end{tabular}

\footnotetext{
${ }^{\mathrm{z}} \mathrm{N}$ is the sample size; $\mathrm{g}$ is the number of genotypes; NPL is the number of polymorphic loci, PPL is the percentage of polymorphic loci (out of 977 ); and $\mathrm{H}$
} is Nei (26) gene diversity. 
related to species of Lasiodiplodia. Isolates of L. theobromae and $L$. iraniensis formed separate clusters. The isolates of $L$. hormozganensis, however, formed two clusters, one consisting of 23 isolates and the other consisting of 2 isolates.
According to Nei's unbiased measures of genetic similarity, the percent genetic similarity between the 25 isolates of $L$. hormozganensis ranged from 52 to $87 \%$ (avg. 72\%) (Fig. 1). The genetic similarity among populations of L. hormozganensis from

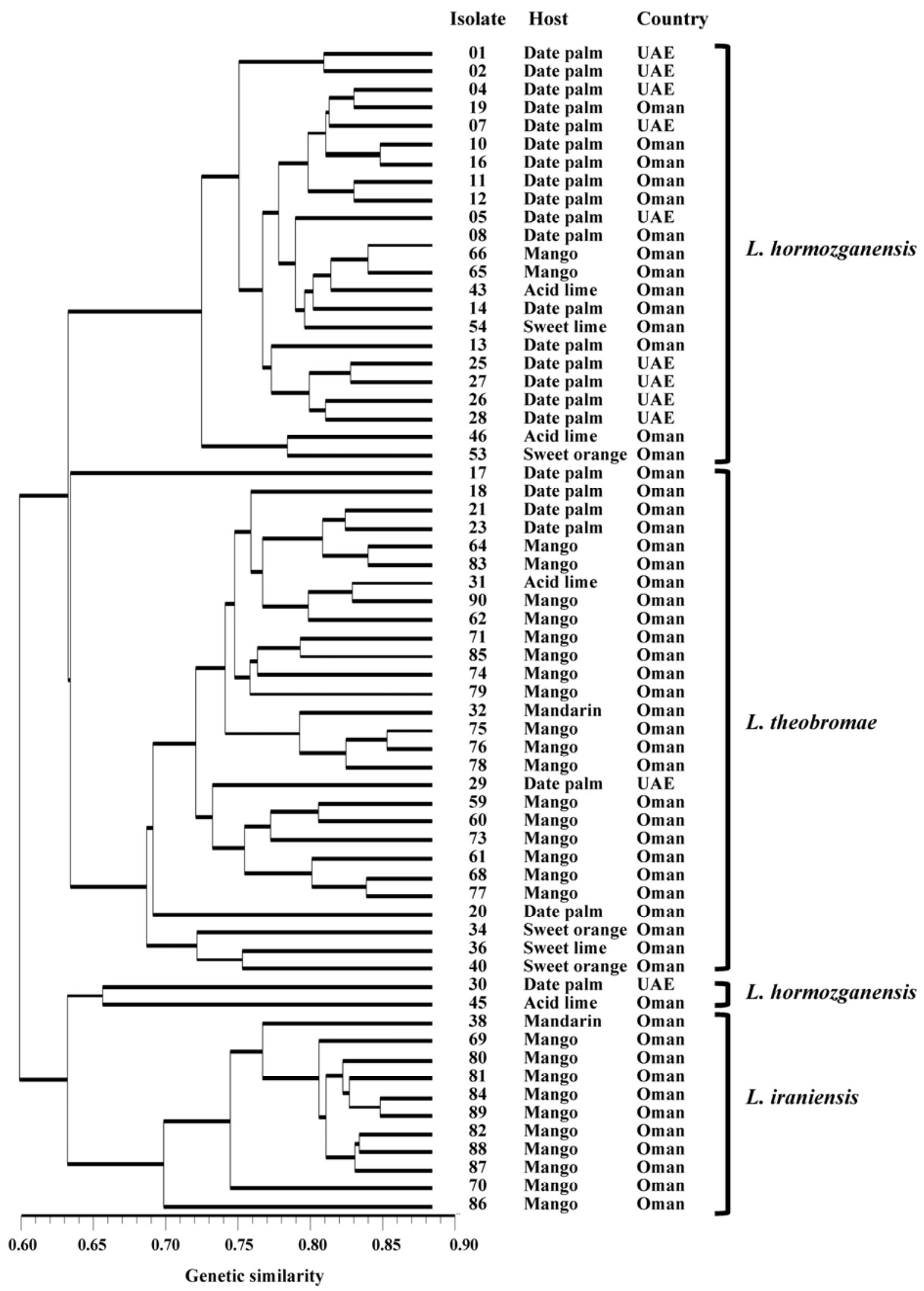

Fig. 2. Unweighted pair group method with arithmetic mean (UPGMA) dendrogram illustrating the genetic similarity (27) of 64 isolates of Lasiodiplodia from date palm, Citrus spp. (acid lime, sweet orange, mandarin, and sweet lime), and mango based on amplified fragment length polymorphism (AFLP) fingerprinting analysis. 
Oman and the UAE was $97 \%$. The genetic similarity between populations from date palm and Citrus, date palm and mango, and mango and Citrus in Oman was 95, 92, and 92\%, respectively. There was no clustering of isolates based on place of origin or host plant (Fig. 2).

Isolates of $L$. theobromae shared a 58 to $84 \%$ (mean $71 \%$ ) level of genetic similarity. They grouped into different clusters, with no relationship between clustering of isolates and hosts from which they were obtained (Fig. 2). The level of genetic similarity between populations of $L$. theobromae from date palm and Citrus, date palm and mango, and mango and Citrus in Oman was 93, 97, and 93\%, respectively.

Partition of genetic variation. AMOVA analysis indicated low levels of genetic differentiation among populations of $L$. hormozganensis obtained from Oman and the UAE $\left(\mathrm{F}_{\mathrm{ST}}=0.025\right)$ and from date palm, Citrus, and mango in Oman (0.0485) (Table 3). The level of genetic differentiation was also low (0.0703) among populations of $L$. theobromae from date palm, Citrus, and mango. Most of the genetic variation was found within populations obtained from different hosts and countries (93 to 98\%). The rate of gene flow between populations obtained from different hosts and geographical locations within each species was high (6.6 to 19.5) (Table 4).

\section{Discussion}

Three species of Lasiodiplodia were isolated from diseased date palm, acid lime, and mango in Oman. L. hormozganensis was associated with root necrosis on date palm, and dieback of acid lime and mango. The pathogen reproduced the same field symptoms when inoculated on date palm, acid lime, and mango. Another species, L. iraniensis, was isolated from mango and acid lime showing gummosis and dieback. It also reproduced the same symptoms upon inoculation on mango and acid lime seedlings. The third species, L. theobromae, was found associated with root necrosis on date palm and dieback in acid lime and mango. It was pathogenic and produced root necrosis and wilt on date palm, and gummosis and dieback symptoms on acid lime and mango.

L. hormozganensis has only recently been reported in Iran on Mango and Olea spp. (1). L. iraniensis has been reported in Iran and Australia on Citrus, mango, and others $(1,30)$, while L. theobromae is widely distributed in different parts of the world $(19,22)$. This is the first record of L. hormozganensis as a causal agent of root necrosis of date palm and dieback and wilt of acid lime.

Analysis of the genetic diversity in populations of three Lasiodiplodia species from different hosts and geographical origins indicated moderate levels of genetic diversity $(\mathrm{H}=0.2663$ to $0.3105)$ and a high number of genotypes. These levels of diversity are moderate compared to the relatively high levels reported for $L$. theobromae on pear (Pyrus sp.) in India (0.36), cacao (Theobroma cacao) in Cameroon (0.48), and on Pinus (0.63), Eucalyptus (0.67) and Acacia species $(0.51)$ in Venezuela $(16,25,31)$. The higher level of genetic diversity in India and Venezuela could be related to a longer history of $L$. theobromae in these countries compared to Oman and the UAE. The high number of genotypes of $L$. theobromae, L. hormozganensis, and L. iraniensis in Oman could be attributed to introduction of these pathogens into Oman from multiple sources $(6,7,9,11)$.

In this study, $L$. iraniensis and $L$. hormozganensis are reported for the first time in Oman; L. theobromae was reported in Oman in the 1970s (32). However, L. iraniensis had a higher level of genetic diversity $(\mathrm{H}=0.311)$ in Oman than either L. hormozganensis (0.250) or L theobromae (0.233). This suggests that L iraniensis, and possibly $L$. hormozganensis, have been in Oman longer, but misidentified as L. theobromae. This is supported by findings from this study and other studies about the difficulty of distinguishing among the three species due to high morphological similarity and almost identical ITS rDNA sequences $(1,8)$. The use of EF1 $\alpha$ gene sequences helped identity the isolates to the species level. In addition, AFLP-based clustering of isolates of Lasiodiplodia helped group them into clusters of species to which they belong.

Date palm has been grown in Oman for thousands of years, compared to Citrus species and mango, which were introduced during the past five centuries. Despite the long history of date palms in Oman, the population of L. hormozganensis from Citrus was more genetically diverse $(0.2560)$ than the populations from date palm (0.2072) and mango (0.0878). This suggests that $L$. hormozganensis was introduced into Oman on Citrus species imported from different countries; after that it infected other plant species in Oman, including date palms and mangoes. This hypothesis is supported by two pieces of evidence. First, the earliest report of $L a$ siodiplodia in Oman was on Citrus in the 1970s (32), but Lasiodiplodia was not reported on date palms and mangoes until the 1990s (24). Previous studies have shown that the longer a pathogen is in an area or on a crop, the greater its genetic diversity $(3,5,7)$. Second, this study found low levels of genetic differentiation among populations of L. hormozganensis and $L$. theobromae from different hosts. This implies a lack of host specialization in $L$. hormozganensis and L. theobromae and therefore provides evidence for transmission and multiple infections of date palm, Citrus, and mango with similar genotypes of L. hormozganensis and L. theobromae. The lack of host specialization, as evidenced by the molecular data, was supported by the pathogenicity tests, which indicated that isolates of the same species were not more pathogenic on their host of origin. This has also been reported in other hostpathogen interactions $(3,14)$. However, it was noted from isolation frequency that some Lasiodiplodia spp. were more common on certain host plants than on others. Since the number of isolates from date palm, mango, and Citrus spp. was relatively small (11 to 29 isolates), a larger study is in progress to evaluate the hostpathogen interaction among Lasiodiplodia species and other plant species in Oman.

Pairwise genetic differentiation indicated low to moderate levels of genetic differentiation among populations of L. hormozganensis from Oman and the UAE. This was further supported by UPGMA analysis, which indicated a lack of evidence for clustering of isolates of Lasiodiplodia according to host plant or place of origin. These findings imply frequent movement of pathogen inoculum across geographically separated districts. Most farms in Oman and the UAE follow a traditional system for growing crops. In this system, date palm is planted on almost every farm and in home

Table 4. Variation as measured using amplified fragment length polymorphisms (AFLPs) among and within populations of Lasiodiplodia hormozganensis and $L$. theobromae from different hosts and geographical regions based on hierarchical analysis of molecular variance (AMOVA)

\begin{tabular}{|c|c|c|c|c|c|c|c|}
\hline Source of variation & df & Sum of square & Variance component & Percent variation & $\mathbf{F}_{\text {ST }}$ & $P$ value & Gene flow \\
\hline \multicolumn{8}{|c|}{$\begin{array}{l}\text { L. hormozganensis } \\
\text { (Oman and UAE; date palm) }\end{array}$} \\
\hline Among & 1 & 127.278 & 2.657 & 2.50 & 0.0250 & 0.07235 & 19.5 \\
\hline Within & 16 & $1,658.500$ & 103.656 & 97.5 & & & \\
\hline \multicolumn{8}{|c|}{ L. hormozganensis (3 hosts) } \\
\hline Among & 2 & 274.322 & 5.47683 & 4.85 & 0.0485 & 0.04497 & 9.5 \\
\hline Within & 22 & $2,362.078$ & 107.36717 & 95.15 & & & \\
\hline \multicolumn{8}{|c|}{ L. theobromae (3 hosts) } \\
\hline Among & 2 & 360.066 & 8.58211 & 7.03 & 0.0703 & 0.00000 & 6.6 \\
\hline Within & 25 & $2,838.041$ & 113.52165 & 92.97 & & & \\
\hline
\end{tabular}


gardens. In Oman, most growers also plant mango and Citrus on their farms, encouraging movement of isolates of Lasiodiplodia among these crops. These pathogens are also disseminated on date palm offshoots and in potting media $(4,6,12)$. The low level of genetic differentiation (0.025) between date palm populations of $L$. hormozganensis from Oman and the UAE may be related to the frequent exchange of planting material between the two countries. This has been a common practice, especially during the last century (6).

The current study suggests that traditional farming practices of date palm, Citrus, and mango in Oman played an important role in the movement of Lasiodiplodia species between hosts and countries. It also provides evidence for the origin of Lasiodiplodia in Oman. This is also the first report of L. hormozganensis as a pathogen of date palm and acid lime, of $L$. hormozganensis and $L$. iraniensis in Oman, and of L. hormozganensis in the UAE. Future management strategies should focus on formulating quarantine measures to reduce the rate of movement of pathogens across districts or into Oman and the UAE. Growers should avoid some cultural practices, such as flood irrigation and movement of soil, that are known to help spread pathogens in the same farm or from other sources.

\section{Acknowledgments}

We thank Prof. Scot Nelson and Dr. Fred Brooks for valuable comments on the manuscript. Special thanks are due to farmers for help in collection of samples, technicians and research assistants for technical help, and SQU for hosting the study and for funding the study through the strategic project SR/AGR/CROP/10/01 and the internal project IG/AGR/CROP/13/01

\section{Literature Cited}

1. Abdollahzadeh, J., Javadi, A., Goltapeh, E. M., Zare, R., and Phillips, A. J. L. 2010. Phylogeny and morphology of four new species of Lasiodiplodia from Iran. Persoonia 25:1-10.

2. Al-Adawi, A. O., Deadman, M. L., Al-Rawahi, A. K., Al-Maqbali, Y. M., Al-Jahwari, A. A., Al-Saadi, B. A., Al-Amri, I. S., and Wingfield, M. J. 2006. Aetiology and causal agents of mango sudden decline disease in the Sultanate of Oman. Eur. J. Plant Pathol. 116:247-254.

3. Al-Sa'di, A. M., Drenth, A., Deadman, M. L., and Aitken, E. A. B. 2008. Genetic diversity, aggressiveness and metalaxyl sensitivity of Pythium aphanidermatum populations infecting cucumber in Oman. Plant Pathol. 57:45-56.

4. Al-Sa'di, A. M., Drenth, A., Deadman, M. L., Al-Said, F. A., Khan, I., and Aitken, E. A. B. 2008. Potential sources of Pythium inoculum into greenhouse soils with no previous history of cultivation. J. Phytopathol. 156:502-505.

5. Al-Sa'di, A. M., Drenth, A., Deadman, M. L., de Cock, A. W. A. M., AlSaid, F. A., and Aitken, E. A. B. 2008. Genetic diversity, aggressiveness and metalaxyl sensitivity of Pythium spinosum infecting cucumber in Oman. J. Phytopathol. 156:29-35.

6. Al-Sadi, A. M. 2013. Phylogenetic and population genetic analysis of Ceratocystis radicicola infecting date palms. J. Plant Pathol. 95:47-55.

7. Al-Sadi, A. M., Al-Ghaithi, A. G., Al-Balushi, Z. M., and Al-Jabri, A. H. 2012. Analysis of diversity in Pythium aphanidermatum populations from a single greenhouse reveals phenotypic and genotypic changes over 2006 to 2011. Plant Dis. 96:852-858.

8. Al-Sadi, A. M., Al-Jabri, A. H., Al-Mazroui, S. S., and Al-Mahmooli, I. H. 2012. Characterization and pathogenicity of fungi and oomycetes associated with root diseases of date palms in Oman. Crop Prot. 37:1-6.

9. Al-Sadi, A. M., Al-Moqbali, H., Al-Yahyai, R., Al-Said, F., and AlMahmooli, I. 2012. AFLP data suggest a potential role for the low genetic diversity of acid lime (Citrus aurantifolia) in Oman in the outbreak of witches' broom disease of lime. Euphytica 188:285-297.

10. Al-Sadi, A. M., Al-Ouweisi, F. A., Al-Shariani, N. K., Kaplen, E., AlAdawi, A. O., and Deadman, M. L. 2010. Histological changes in mango seedlings following infection with Ceratocystis manginecans, the causal agent of mango decline. J. Phytopathol. 158:738-743.

11. Al-Sadi, A. M., Al-Raisi, I. J., Al-Azri, M., Al-Hasani, H., Al-Shukaili, M. S., Al-Shuraiqi, S. M., Al-Fahdi, K. O., and Deadman, M. L. 2012. Popu- lation structure and management of Podosphaera pannosa associated with peach powdery mildew in Oman. J. Phytopathol. 160:647-654.

12. Al-Sadi, A. M., Al-Said, F. A., Al-Jabri, A. H., Al-Mahmooli, I. H., AlHinai, A. H., and de Cock, A. W. A. M. 2011. Occurrence and characterization of fungi and oomycetes transmitted via potting mixtures and organic manures. Crop Prot. 30:38-44.

13. Al-Sadi, A. M., Al-Said, F. A., Al-Kiyumi, K. S., Al-Mahrouqi, R. S., AlMahmooli, I. H., and Deadman, M. L. 2011. Etiology and characterization of cucumber vine decline in Oman. Crop Prot. 30:192-197.

14. Al-Sadi, A. M., and Deadman, M. L. 2010. Influence of seedborne Cochliobolus sativus (anamorph: Bipolaris sorokiniana) on crown rot and root rot of barley and wheat. J. Phytopathol. 158:683-690.

15. Barnett, H. L., and Hunter, B. B. 1998. Illustrated genera of imperfect fungi. American Phytopathological Society, St. Paul, MN.

16. Boyogueno, A. D. B., Slippers, B., Perez, G., Wingfield, M. J., and Roux, J. 2012. High gene flow and outcrossing within populations of two cryptic fungal pathogens on a native and non-native host in Cameroon. Fungal Biol. 116:343-353.

17. Carbone, I., and Kohn, L. M. 1999. A method for designing primer sets for speciation studies in filamentous ascomycetes. Mycologia 91:553-556.

18. Excoffier, L., Laval, G., and Schneider, S. 2005. Arlequin (version 3.0): An integrated software package for population genetics data analysis. Evol. Bioinform. Online 1:47-50.

19. Ferrari, F. D., Ochoa, C. F. M., and Subero, M. L. J. 1996. Dieback and gummosis induced by Lasiodiplodia theobromae (Pat.) Griffon \& Maubl. on three citrus tree species. Anales Bot. Agric. 3:46-49.

20. Fu, G., Huang, S. L., Wei, J. G., Yuan, G. Q., Ren, J. G., Yan, W. H., and Cen, Z. L. 2007. First record of Jatropha podagrica gummosis caused by Botryodiplodia theobromae in China. Australas. Plant Dis. Notes 2:75-76

21. Kimati, H., Amorim, L., Rezende, J. A. M., Bergamin Filho, A., and Camargo, L. E. A. 2005. Manual de Fitopatologia vol. 02 - doen, cas das plantas cultivadas. Editora Agronômica Ceres Ltda, São Paulo, SP.

22. Latha, P., Prakasam, V., Kamalakanna, A., Gopalakrishnan, C., Raguchander, T., Paramathma, M., and Samiyappan, R. 2009. First report of Lasiodiplodia theobromae (Pat.) Griffon \& Maubl. causing root and collar rot disease of physic nut (Jatropha curcas L.) in India. Australas. Plant Dis. Notes 4:19-21.

23. Lee, S. B., and Taylor, J. W. 1990. Isolation of DNA from fungal mycelia and single spores. Pages 282-287 in: PCR protocols: A Guide to Methods and Applications. M. A. Innis, D. H. Gelfand, J. J. Sninsky, and T. J. White, eds. Academic Press, New York, USA.

24. Moghal, S. M., Shivanathan, P., Mani, A., Al-Zidjali, A. D., Al-Zidjali, T. S and Al-Raeesy, Y. M. 1993. Status of Pests and Diseases in Oman: Series 1: Plant Diseases in the Batinah. Ministry of Agriculture and Fisheries, Muscat, Oman

25. Mohali, S., Burgess, T. I., and Wingfield, M. J. 2005. Diversity and host association of the tropical tree endophyte Lasiodiplodia theobromae revealed using simple sequence repeat markers. For. Pathol. 35:385-396.

26. Nei, M. 1973. Analysis of gene diversity in subdivided populations. Proc Nat. Acad. Sci. 70:3321-3323

27. Nei, M. 1978. Estimation of average heterozygosity and genetic distance from a small number of individuals. Genetics 89:583-590.

28. Pillay, K., Slippers, B., Wingfield, M. J., and Gryzenhout, M. 2013. Diversity and distribution of co-infecting Botryosphaeriaceae from Eucalyptus grandis and Syzygium cordatum in South Africa. South Afr. J. Bot. 84:38-43.

29. Rohlf, F. J. 2009. NTSYSpc: Numerical taxonomy system. ver. 2.21c Exeter Software, Setauket, New York.

30. Sakalidis, M. L., Ray, J. D., Lanoiselet, V., Hardy, G. E. S., and Burgess, T. I. 2011. Pathogenic Botryosphaeriaceae asociated with Mangifera indica in the Kimberley region of Western Australia. Eur. J. Plant Pathol. 130:379391.

31. Shah, M. D., Verma, K. S., Singh, K., and Kaur, R. 2011. Genetic diversity and gene flow estimates among three populations of Botryodiplodia theobromae causing die-back and bark canker of pear in Punjab. Arch. Phytopathol. Plant Prot. 44:951-960.

32. Waller, J. M., and Bridge, J. 1978. Plant Diseases and Nematodes in the Sultanate of Oman. PANS 24:313-326.

33. Yeh, R. C., and Boyle, T. J. B. 1997. Population genetic analysis of codominant and dominant markers and quantitative traits. Belg. J. Bot. 129:157.

34. Zaid, A., de Wet, P. F., Djerbi, M., and Oihabi, A. 2002. Diseases and pests of date palms. In: Date Palm Cultivation. A. Zaid, ed. FAO, Rome, Italy. 